\title{
¿Dónde estamos...?
}

A propósito de Santiago. Dónde estamos y hacia donde vamos. A. Galetovic (Ed). CEP Where are we. . ?

Магі́a Ber†rand S. / Dra. en Urbanismo (París)

\section{$<$ Resumen>}

La autora del siguiente artículo toma la pregunta publicada -hecha pública- por el estudio del Centro de Estudios Públicos (CEP) "Santiago: Dónde estamos, y hacia donde vamos", editado por el economista Alexander Galetovic. El traspaso represanticional de las cartografías santiaguinas son acogidas al campo disciplinar.

$<$ Abst ract $>$

The author follows the question that was published (and made public) by the Center of Public Studies (C. E. P.) "Santiago: where are we, and where are we goi ng", edited by econom st Al exander Gal etovic. The transfer of representation of cartographi es of Santiago is accepted by the architecture work field.

<Palabras clave>

URBANISMO SANTIAGO / REPRESENTACIONES URBANAS / CAMPO DISCIPLINAR ARQUITECTO-URBANISTA

$<$ Key words>

URBANI SM, SANTI AGO / URBAN REPRESENTATI ON /

WORK FI ELDS ARCHI TECTURE URBANI SM
¿DÓNDE ESTAMOS.

cuando, para razonar sobre las condiciones, calidades, riquezas o pobrezas de las es-pacialidades vividas por otros, las representamos en clases, códigos, bases de datos?

¿DÓNDE ESTAMOS

cuando ( $¿$ a partir de lo representado?) decidimos los principios y los instrumentos, los contenidos y los medios de regulación "más adecuados para manejar el desarrollo de la realidad así representada...? ¿Dónde se está cuando se toman decisones condicio-nantes de lo que viviremos como entorno?
La reciente publicación del texto editado por A. Galetovic es un aporte doblemente bienvenido. Bienvenido en primer lugar por el tema - crucial $^{1}$ - del de los medios y operaciones de planificación espacial del desarrollo de Santiago Metropolitano. Bienvenido también, en segundo lugar, por su voluntad de colocar la reflexión crítica -y no la descripción ni la apología- en un "dónde"2. Personalmente, quisiera recorrer este texto en dos tiempos. Detenerme primero en el "dónde estamos" de las representaciones presentadas en el texto-soporte a través del cual se organizan los razonamientos sobre la pertinencia de los discursos (las "palabras"3) sobre la interacción planificaciónespacialidad (las "cosas") en la realidad a nivel de la escala metropolitana. Dejando para un segundo tiempo -por venir-el recorrido a través del consecuente "dónde" de la toma de decisiones ${ }^{4}$ para esa escala de planeamiento espacial. El filtro de lectura es, 
en ambos recorridos, aquel de las exigencias y condiciones de representación y de operación ${ }^{5}$ aportadas por la invocación al "dónde".

\section{-"dónde" nos instalamos como c ampo...}

La operación que instala una representación encargada de explicar una realidad no es -nunca- ingenua. Los lenguajes solicitados, discursivos, cartográficos, estadísticos... declaran, necesariamente, cuales son los componentes de la realidad, retenidos, filtrados así como sus nexos explicativos encargados de sustituir a los procesos de la "realidad". Esas operaciones de representación, esas condiciones del razonamiento pueden ser determinantes fundamentales ${ }^{6}$, capaces de caracterizar los ámbitos mismos de decisiones, las responsabilidades, los temas y/o las prioridades de intervención. Operación condicionada por la naturaleza del terreno inicial: por el "dónde" epistémico. Terreno a veces tan "obvio" -tan familiar, tan reiteradoque su condición de operación históricamente fechada pasa inadvertido y su tesis es asumida como calce exacto con la realidad examinada: la distancia, diferencia y tensión entre realidad y operación de representación se olvidan, la representación empieza a ser considerada como "espejo" de lo real".

Sin embargo, la instalación del "dónde" inicial está lejos de ser banal, o detalle menor, o juego de palabras: es, por el contrario, el momento más gravemente responsable de lo que va a hacer emerger como posibilidad de operaciones, como lenguaje de representaciones, como "especie de espacio". Un saber coherente, consistente, eficaz, un saber sobre todo responsable de sus efectos sobre la realidad es necesariamente un saber consciente de la gravedad de los inicios, de los distintos efectos procedentes de los diferentes tipos de operaciones a partir de las cuales construye decisiones que reinserta en la complejidad de la realidad ${ }^{8}$. Más aún: ese saber -responsable- integra los efectos y las consecuencias de esa reinserción: las repercusiones en el día a día de cada persona, las consecuencias irreversibles en la organización como sociedad, desde el primer momento cuando define el suelo epistémico, los lenguajes y las operaciones de representación.

\section{-disciplinar...}

En ese contexto, saludamos con alegría la publicación de un texto bienvenido a la mesa ${ }^{9}$ disciplinar porque portador precisamente, del tema de los nexos complejos entre representaciones ${ }^{10}$-decisiones de planificación ${ }^{11}$ - efectos atribuíbles y/o consecuentes a las decisiones ${ }^{12}$. Bienvenida igualmente la opción de explicar esos nexos de la manera más transparente (¿objetiva?) posible: en este caso, a través de la indentidad término-indicador registrable en las evidencias -irrefutables- de las imágenes satelitales, fotografías aéreas, conteos, registros de cantidades.

La opción es conducida a través de representaciones y lenguajes de clases de objetos discretos cuya representación -cartográfica, cuantitativa- permite operaciones estadísticas y programas SIG: sus resultados trabajan como "espejo de la realidad" 13 ...: los nexos entre términos y decisiones técnicas -instrumentales, programas- $y$ entre éstas y los efectos físicamente tangibles sobre la realidad, son las proximidades, tamaños, conectividades de la distribución de las clases de datos en la espacialidad homogénea de la cartografía euclidiana. Pero: ¿son "espejo fiel" de lo que, en la realidad, constituye el "dónde"? Esa claridad explicativa, esas distancias, esas conectividades... ¿dónde ocurren?. A primera vista, ellas ocurren fuera-del-mundo "natural": libre de las rugosidades climáticas y ambientales asociadas a una topografía tal que es su primer atributo como "dónde"14. También parecen ocurrir ajenas a las dinámicas sociales ison tales en el día a día de los interesados?... ¿Cuál es, en otros términos, el "dónde" caracterizado como deficiente o eficiente?. Mayoritariamente, un "dónde" representacional intensamente abstracto. Un "dónde" necesario y favorable al más alto racionalismo. Importa determinarlo. Saber que es uno de los distintos accesos, parciales, al "dónde" -mayor, inscrito en el mundo ${ }^{15}$ - que es el objeto y el sujeto de todo planeamiento:

1 Crucial: determinante, decisivo del modo de desarrollo. I.e. de la conducción (literalmente, del gobierno) de las condiciones de institucionalización de la sociedad (P. Healey, 1997: F. Choay, 2005). Particularmente por sus efectos sobre las dinámicas económicas: i.e. estancamiento o emergencia de actividades, empleos, inversiones (J. Jacobs, 1997; F.

2 "Dónde" -ubi- uno de los cuatro "términos maestros fundadores del ESPACIO" (en conjunto con quo unde y qua, M. Serres, 1980, 1987, 1993). Ubi: dónde residimos: en qué horizontes, singulares, en cuáles climas, qué historias, con cuáles peligros o bienestares de lugares siempre singulares: invocar un "dónde" implica convocar, trabajar neoecosistemas (A. Magnaghi,): implica, en otros términos, trabajar representaciones inmersas, contextualizadas, en devenir (P. Healey, op cit), esto es, con sistemas de sistemas multiescalares, complejos (I. Stengers, 2002, 1997)

3 En la perspectiva crítica de "Las Palabras y las Cosas" de M. Foucault (1966) o invocado por M. Mer-leau-Ponty, perspectiva diferente al otro sentido otorgado a "cosas" por B. Latour ((2004), indispensable en este segundo caso para trabajar con procesos de complejidad organizada.

4 l.e. los "temas", procesos, medios, instrumentos técnicos espaciales y a-espaciales, orden de precedencia de los niveles implicados en la elaboración de decisiones de ordenamiento territorial, de planeamiento sectorial, de intervenciones temáticas (biodiversidad, patrimonialidad, seguridad, ciudadanía, productividad social y económica...) Cf por ejemplo el reciente A New Vision for Planning. Delivering Sustainable Communities, Settlements and Places. "Mediating Space - Creating Place". The Need for Action elaborado por el Royal Town Planning Institute (2001), UK.

5 Operaciones en el sentido de M. de Certeau (), M. Serres, (op cit) o I. Stengers (op.cit) de construcción de lenguajes para los conceptos operacionales invocados: vivienda, proceso de producción de vivienda, movilidad, accesibilidad, conectividad que impliquen el "dónde" de sus localizaciones tanto como los efectos de su materialización como objeto, espacialidad...sobre el resto del tejido. Y operaciones -analíticas, sintéticas, interpretativas- para trabajar sus intersecciones intersectoriales y multiescalares.

Cuando, por ejemplo, el conjunto de representaciones reemplaza totalmente a la realidad, adquiere valor propio y descarta construcciones del saber o toma de decisiones basadas en el feed-back representación-realidad característico del Planeamiento Espacial Estratégico Colaboracional. Feed-back que, lejos de ser juguete de vaivenes de poder y de intereses cortoplacistas opera con la lógica de ir recapturando las transformaciones que su propia agenda va produciendo. Cf especialmente el conjunto de documentos de P. Healey (op cit).

M. Foucault, M. Serres, op cit; I. Stengers, op cit.

8 Clingermayer J.C. (2004); P. Healey (1997), M. Webber (1970).

En el sentido Arendtiano de mesa como metáfora del "dominio de lo público" (public realm).

10 Teóricas, conceptuales y sus lenguajes complementarios discurso-cartografía-estadística.

11 Trazado espacial de la herramienta límite urbano asociado a expansión del contínuo. Cf Segunda Parte.

12 Contaminación del aire, congestión, vias expresas, política habitacional, transporte, manejo de la basura. Cf Tercera Parte. Políticas sectoriales.

13 M. Foucault, op cit; G. Bachelard, op cit, M. Bertrand (2005).

14 M. Bertrand (2006). El horizonte de la ocupación total. En curso.

15 Mundo en el sentido Arendtiano del término: de neo-ecosistemas naturales-tecnológicos, culturales. Cf. H. Arendt (), A. Magnaghi (). 
"dónde" de saber y de gobierno ${ }^{16}$. Que éste puede ser uno de los mejores inicios, paso ineludible consecuente con definiciones iniciales ${ }^{17}$ a partir del cual profundizar el "dónde" del planear espacial ${ }^{18}$

\section{- ¿empí гісо?}

El primer "dónde estamos" textual declara su voluntad de "estar" en el ámbito de actuaciones institucionales conducidas por precisas "operaciones de saber" disciplinar. "Dónde" que marca sus distancias y sus diferencias con discursos doctrinales ${ }^{19}$

no asumidos como tales asociados, arbitrariamente, a decisiones dichas técnicas porque desmundadas, porque aplicadas de manera acrítica, pasiva ${ }^{20}$. El "dónde" textual busca instalarse, por el contrario, en un campo empírico y pragmático vía indicadores neurálgicos encargados de representar y medir que ocurre en la realidad. Búsqueda característica de la acción disciplinar. Pero, atención: los indicadores -clases- se localizan en la representación euclidiana. Sus lecturas e interpretaciones operan en ese ámbito ${ }^{21}$. El espacio disciplinar que se desprende es, necesariamente, temático y desmundado: ajeno a la naturaleza procesual de las experiencias ${ }^{22}$ y de las decisiones -inmersas, multiescalares- de su planeamiento ${ }^{23}$. El primer "dónde" textual instala uno de los caminos clásicos que han intentado ir de "las palabras a las cosas" 24 sin percatarse, siempre, de los riesgos de ese modo de construcción ${ }^{25}$.

\section{-que da cuenta de temas}

Así, uno de los grandes méritos del conjunto de artículos que construyen el texto reside en el apego estricto a esa voluntad de instalar nexos explícitos entre "palabras" y "representación de la realidad" a partir de y en interacción con el "plano de consistencia" del pensamiento ${ }^{26}$ y operaciones cartográficas. A medida que el plano de consistencia es interrogado por los diferentes filtros conceptuales, "responde" desde la dimensión cartográfica euclidiana. Esta postura declaradamente empírica -disciplinarmente reconfortante- busca perfilar una actividad capaz de reencontrar la realidad de las relaciones sociedad-entorno, capaz también de superar su reducción a espacio artefacto y/o su reificación instrumental como "zonas" estancas. La búsqueda de coherencia entre discurso conductor y lo que "dicen" los datos desde el plano de consistencia euclidiano permite, retrospectivamente, cuestionar la inconsistencia de las afirmaciones doctrinales y-prospectivamente- plantear escenarios que convocan decisiones de política y de gobierno, en el sentido fuerte del término. Estos discursos de evidencias interrogan, de manera precisa y fechable-empírica y no doctrinalmente- a instituciones responsables de decisiones que recién empiezan a revelar sus consecuencias.

\section{-y solicita instalar ргеcisos "cables a †іегга"...}

En otros términos, y con diferentes énfasis, el primer paso -incompleto y parcial respecto a sus propias ambiciones como "dónde" - importa en su llamado de atención, en su rol de antídoto a la incapacidad de conceptualizaciones operacionales. Importa en el llamado a decisiones que no pierdan el "cable a tierra" con la realidad que las convoca. Importa también como primer paso a exigencias, a consistencias capaces de interrogar zappings arbitrarios esgrimidos -equivocadamente- como "teoría".

\section{-рего solo primer paso}

Establecido lo cual, importa reiterar los riesgos y los posibles bloqueos de acceso al reencuentro -idealmente dialógico- con el "dónde" del planear si ese primer paso -parcial, incompleto- en vez de prolongar su dinámica, su condición de ser movimiento hacia... es asumido como la representación confiable completa, cerrada: como espejo fiel del "dónde" de los procesos reales. Inmovilismo, cerramiento que lo transformarían -a su vez- en discurso doctrinal no asumido como tal. El riesgo de deriva es fuerte, por efecto de la naturaleza misma de los lenguajes de la representación como de la tentación de hipostasiar.

\section{- . . .encruci jada}

Encierro capaz de bloquear el acceso no sólo a la noción disciplinar de territorio ${ }^{27}$ Encierro portador del riesgo aún mayor de razonamiento plano, uniescalar si las representaciones tienden a ocultar la multiescalaridad característica de los procesos reales ${ }^{28}$ : ninguna situación arealmente local -ningún "dónde"- se determina por o se resuelve con escalas unicamente locales ${ }^{29}$. Hablamos de escalas espaciales, temporales, procesuales, funcionales presentes en los diferentes componentes de los temas examinados: de articulaciones entre lógicas y dinámicas diferentes ${ }^{30}$. Sin olvidar, asociado a lo anterior, que el traslado de las representaciones hacia escalas mayores o menores a su punto de construcción los modifica más intensamente de lo que se quisiera $^{31}$.

16 Cf. I. Stengers (2002) y (2003); el linaje del pensamiento de H. Arend. De saber gobernar.

in Introducción. ¿Quién es Santiago?. Definiciones.

18 L. Sandercock (2004) sistematiza algunas pistas. Se trata de rasgos del "dónde" presentes en planeamientos en curso, cf los casos de Lyon Metropolitano, del Gran Vancouver, Turín...

Por naturaleza, parte de los discursos no-pacificadores, polémicos, interesados en la dominación. Cf I. Stengers (2002), B. Latour (2004), M. Bertrand (2006).

20 Encerradas en su lógica discursiva, las doctrinas son ciegas y sordas a la heterogeneidad, complejidad, "flecha del tiempo" de la realidad.

${ }_{21}^{20}$ Encerradas en su lógica discurselard (1934/1963).

Caracterizada también tempranamente por M. Webber in "The Urban Place and the Nonplace Urban Realm”, in M. Webber (ed) Explorations into Urban Structure. (1964) Philadelphia, University of Pennsylvania Press.

23 Manejo, conducción, control, regulación, gestión. B. McLoughlin. Planeamiento Urbano y control; P. Healey (1987); Faludi (2004).

24 F. Choay (1980) La règle et le Modèle. Paris, Le Seuil.

25 F. Farinelli (1998).

25 F. Farinelli (1998)

26 F. Farinelli, op cit.

27 ¿No está en entorno ya reducido términos genéricos a una "geografía" y a un"clima excepcional".

28 Bertrand M (2004).

29 M. Webber (1964/1996)

30 Articulaciones que van más allá de los límites autoimpuestos de los procedimientos sistematizados por I. MacHarg o por los métodos del riesgo ecológico: ambos permanecen anclados en representaciones de clases de objetos asociados por relaciones causa-efecto. Las exploraciones más complejas recientes -sintomáticamente asociadas a la biodiversidad- muestran, sin embargo, pistas prometedoras.

31 Caso de las transformaciones de las densidades explorado magistralmente por $\mathrm{H}$. Le Bras, a partir del cual deriva las nociones de urbanización filamentosa, ingobernable con la instrumentalidad clásica. 


\section{-presente en todo primer paso}

Todo eso, y mucho más está ciertamente presente en el grupo-autor de este texto, $Y$ necesita ser así en la medida misma que en nombre de las exigencias del "dónde", buscan reencontrar la realidad. Y las pistas del avance residen en lo que ya sabemos: que la "producción del espacio"32 difiere de representación, particularmente en presencia de determinadas operaciones cartográficas ${ }^{33}$ Que los poderes distorsionantes y los riesgos de traición de las representaciones desmundadas pueden ser desvastadores cuando no se los reconoce como "operación". Que la representación que busca implicar las prácticas, los habitus, los capitales -tangibles e intangibles ${ }^{34}$ - que materializan, sin embargo, la validez o las equivocaciones de las decisiones disciplinares podría tener dimensiones de diagramática, fuzzyness integradas a los ordenamientos por clases de objetos: Ios caminos que buscan caracterizar el "dónde" de procesos de intercambio, transformación, cambio parecen avanzar en ese sentido. ¿Qué dónde metropolitano revelarían, cuáles aquí, allí, diferentes quizá de las condiciones satisfactorias declaradas por el espacio liso euclidiano. Porque se trata de vidas, de actividades propulsoras de economías "durables"35. De existencias humanas y de la vida de todos los reinos que, conjuntamente, construyen precisamente sus "dónde" singulares. Paso a paso, ¿queremos iniciar el reencuentro con la realidad?

\section{Bibliografía}

Arendt H. (1961/1983). Condition de l'homme moderne. Paris. Payot.

Bachelard G. (1934/1963) Le Nouvel esprit Scientifique. Paris. P.U.F.

Bertrand M (2004b) El planeamiento espacial metropolitano revisitado. Condiciones, contextos, responsabilidad de sus fundamentos epistemológicos. SeminarioTaller GTZ.
Certeau, M. (1975) L'écriture de l'histoire. Paris, Folio Gallimard.

Clingermayer J.C. (2004). Heresthetics and Happenstance: Intentional and Uninten-tional Exclusionary Impacts of the Zoning Decisionmaking Process. Urban Studies, 41, 2.

Choay F.(2004). Le De re aedificatoria et l'institutionnalisation de la société. Paris, Conférence Louvre.

Farinelli F.(1998) Did Anaximander ever Say (or Write) any Words? The nature of Cartographical Reason Ethics, Place and Environment, 1, 2.

Foucault M. (1966) Les mots et les choses. Une archéologie des sciences humaines. Paris, Gallimard.

Healey P., Khakee A., Motte A., Needham B. (1999). European Development in Stra-tegic Planning, European Planning Studies, 7, 3.

Healey P. (1997). Collaborative Planning. Shaping Places in Fragmented Societies, London, MacMillan Press Ltd.

Jacobs J. (1970) The Economy of Cities. New York, Random House, Vintage Books.

Jacobs J (1985) Cities and the Wealth of Nations. Principles of Economic Life. New York, Random House, Vintage Books.

Khakee A., Barbanente A. (2003) Negotiative land-use and deliberative environmental Planning in Italy and Sweden. International Planning Studies, 8, 3.

Latham A., McCormack D.P. (2004). Moving Cities: rethinking the materialities of Ur-ban geographies. Progress in Human Geography, 28,6 .

Latham A. (2003). Urbanity, Lifestyle and Making Sense of the New Urban Cultural Economy: Notes from Auckland, New Zeland. Urban Studies, 40, 9.

Latour B.(2004) Why Has Critique Run out of Steam?. From Matters of Fact to Mat-ters of Concern. Critical Inquiry, 30, Winter.

Le Bras H. (1993/1997) La Planète au Village. DATAR. Editions de l'aube.

Lefebvre H.(1986/2000). La Production de l' Espace, Paris, Anthropos.
Lo Piccolo F.; Schilleci (2005) Local development Partnership Programmes in Sicily: Planning Cities without Plans. Planning Practice \& Research, 20, 1.

Magnaghi A.(2003) Le Projet Local. Bruxelles Mardaga.

Mareggi M. (2002). Innovation in Urban Policy: The Experience of Italian urban Time Policies, Planning Theory \& Practice, 3, 2.

Perkins Ch. (2004). Cartography - Cultures of Mapping: power in practice. Progress in Human Geography, 28, 3.

Pinson G. (2002). Political Government and Governance: Strategic Planning and the Reshaping of Political Capacity in Turin International Journal of Urban and Regiona Research, 26, 3 .

Rossi M.E., Rosso E. (2000) Torino Internazionale. Plan stratégique pour la promotion de la ville 2000-2010. turin_fr_sansschema.doc

RTPI (2001) A New Vision for Planning. Delivering Sustainable Communities, Settle-ments and Places. "Mediating Space - Creating Place". The Need for Action elaborado por el Royal Town Planning Institute.

Sandercock L. (2004). Towards a Planning Imagination for the 21st Century. JAPA, 70, 2

Sayre N.F. (2005). Ecological and Geographical Scale: parallels and potential for inte-gration. Progress in Human Geography 29, 3.

Serres M.(1980). Hermes V. Le Passage du NordOuest. Paris, Ed. de Minuit.

Stengers I (2002) Penser avec Whitehead. Paris Seuil.

Stengers I(1993). L' invention des sciences Modernes.

Stengers, I;. Schlanger J.(1991) Les Concepts Scientifiques: invention et pouvoir. Gal-limard Folio.

Stengers I.(1997, 2003). Cosmopolitiques I y II. Paris, Ëditions La Découverte.

Sui D.Z. (2004). GIS, Cartography and the "Third Culture": Geographic Imaginations in the Computer Age. The Professional Geographer, 56,2

Webber M. (1964/1996), L'Urbain sans Lieu ni Bornes. L'Aube.

H. Lefevbre (1986/2000), A. Laham (2004)

33 G. Bachelard (1934/1960) habla de "los dilemas de la filosofía geométrica" cuando busca las síntesis entre geometrías euclidianas y no-euclidianas. Partiendo de la base que existe una "geometrización", una espacialidad del pensar que pesa sobre lo que va a ser asumido como percepción objetiva. F. Farinelli (1998) va más lejos: "all the history of Western thought is nothing but the history of the raising of carto-graphical representation, and of reason here embodied, from the dark rigidity of death to the rarefied splendours of Pure Reason". Dada su importancia en prácticamente todas las ciencias de la vida -naturales y humanas-, el tema de los lenguajes de las representaciones espaciales (temporales) empieza a ser uno de los medios de construcción de saber más indagados. Cf D.Z. Sui (2004); Ch. Perkins (2004).

34 Latham A., McCormack D.P. (2004); Mareggi M. (2002)

35 La lección de J. Jacobs (1985), valorada sin embargo por el premio Nobel de Economía 1995 R. Lu-cas (University of Chicago) aún no logra ser asumida al momento de comprender la naturaleza de una organización de espacialidad. De la espacialidad común a todos los reinos. Cf. A. Khakee, A. Barbanente (2003), N.F.Sayre (2005), S.D. Brody (2003). 